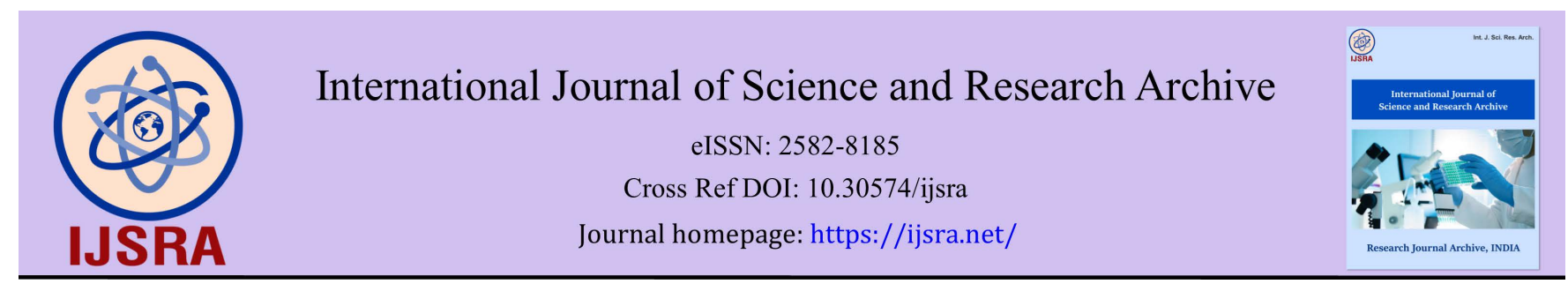

(RESEARCH ARTICLE)

Check for updates

\title{
Growth of tomato plantlets in soilless culture, enriched with egg shell waste and algae
}

\author{
Handan Ertürk * \\ Department of Bioengineering, Konya Food and Agriculture University, Melikşah mah. Beyşehir cad. No. 9, 42080 Meram, \\ Konya, Turkey
}

International Journal of Science and Research Archive, 2021, 03(02), 161-167

Publication history: Received on 23 July 2021; revised on 23 September 2021; accepted on 25 September 2021

Article DOI: https://doi.org/10.30574/ijsra.2021.3.2.0117

\begin{abstract}
In this research, it was aimed to use the Chlorella Vulgaris algae, and eggshell waste (ESW) as different mineral sources for tomato plant nutrition in soilless culture. Algae is seen as safe, sustainable energy source. Egg shell waste is known to be valuable for high calcium content and minerals therefore, has been considered as mineral enrichment source. Although there are several papers on the soil nutrition, there is not as much information on eggshell waste and algae use for plant production in soilless culture. In the controlled atmosphere of the laboratory, a set-up was constructed for pumping the liquid medium (hydroponics) circulating in the tubes holding the tomato plantlets. The liquid nutrient solutions used for soilless culture treatments were media enriched with algae, enriched with ESW and blank (hydroponic only). Research was conducted for 3 months, the final weight of harvested tomatoes and mineral uptake of the plant (stalk and tomato) for different treatments were measured. Algae added medium gave higher results in tomato weight, than ESW added and blank treatments. Results showed that algae and ESW addition led to increased Ca content in harvested tomato, as well as minerals such as $\mathrm{B}, \mathrm{K}, \mathrm{Mg}$, and $\mathrm{Zn}$. The results were as expected in terms of increase in mineral contents, but the statistics showed no significant difference between treatments.
\end{abstract}

Keywords: Soilless culture; Egg shell Waste; Algae; Environment; Sustainability

\section{Introduction}

Soilless culture studies often called as hydroponics are used for controlled environment due to better nutrient supply control through the liquid medium and environmental control stability, such as light, temperature and humidity controls in the greenhouses.

'The production volume of eggs worldwide exceeded 76.7 million metric tons in 2018, up from 73.9 million metric tons in 2016. Since 1990, the global egg production volume has increased by over 100 percent'. Egg shell constitutes approximately $11 \%$ of the egg weight, a considerable amount is discarded as eggshell.

Eggshell was used as calcium supplement on tomato production in the 'aquaponic' system by Zahan et al.[1]. The source of calcium (egg shell) was added to aquaponics to feed Tillapia fish and tomato seedlings symbiotically in the pond. They found higher production of tomato and fish, showing the potential of eggshell powder as source of calcium[1]. Algal application (besides yeast and vermiwash) on the vegetative growth and nutrient status of citrus lemon seedlings were studied[2]. The natural extracts mentioned were used as foliar fertilizers on seedlings grown in soil. The results showed that the algal extract and yeast extract application increased leaf weight of lemon seedlings so they were recommended as fertilizer improving vegetative growth.

\footnotetext{
${ }^{*}$ Corresponding author: Handan Ertürk*

Department of Bioengineering, Konya Food and Agriculture University, Melikşah mah. Beyşehir cad. No. 9, 42080 Meram, Konya, Turkey.

Copyright (C) 2021 Author(s) retain the copyright of this article. This article is published under the terms of the Creative Commons Attribution Liscense 4.0
} 
Egg shells added to organic wastes as a supplement through composting was studied as potential market for calcium rich commercial compost[3]. They pointed out the potential of eggshell waste composted with organic materials for increased uptake of lead in aqueous medium.

The various applications of egg shells are studied by some researchers e.g. Ahmad, Guru Mittal et.al. [4,5,6]. Egg shell waste function as low-cost adsorbent material for metals in aqueous solutions [4] and applications of egg shells as adsorbents were shown $[5,6]$.

According to reference, dried and powdered egg shells are known as a rich source of calcium and protein[7]. Calcium deprivation causes illness in tomato plant known as Fusarium oxysporum infection and it is seen as rotten or discoloration in fruit surface. The cell wall integrity of plant enriched with calcium is important for plant health as the increased uptake of calcium in plants leads to decrease in pathogen infection[8].

The increased use of biological fertilizers increases crop quality and decreases adverse effects such as illnesses in plants. They reported the rural development and environmental protection through the use of bio fertilizers [9]. The improved plant growth, fruit yield and nutrition was studied by reference[10]. The increased importance of sustainability of biological systems leads to evaluation of organic agricultural wastes and adding value to food industry. The application of organic fertilizers contributes to soil physical (e.g. structure development), biological (e.g. microflora) and chemical (nutritional) values. The increased long-term biological matter crop quality and soil attributes, such as porous structure and water holding capacity were reported to be increased[11] .

Effect of using microalgae (Chlorella vulgaris) on nutrients of tomato grown in soilless culture in the greenhouse was presented[12]. Their results showed significant mineral nutrient savings when the algae was used as a supplement in the reduced nutrient conditions (than the usual that they used). They suggested that the algae can also increase some mineral content as $\mathrm{P}, \mathrm{Na}$ and $\mathrm{Mg}$, besides the increase in tomato fruit weight and volume.

But there is not as much published data on the bioavailability of nutrients and the response of plants to organic fertilizers in soilless culture compared to soil papers. The main purpose of this research was to utilize egg shell waste and algae as treatments for tomato nutrition in soilless culture. The ESW plus algae considered as bio fertilizer, was investigated in terms of nutrients bioavailability to plants.

This paper is based on the findings of the second part of our research project and the first findings of the research in soil that has been published[13]. This paper is based on the findings of the study in 'soilless culture' which is important, because it is innovative in terms of a sustainable system design. The purpose of the research in broader sense, was to reduce the use of chemical fertilizers and use biological counterparts in order to achieve the environment and human health benefits. Environmental research should be based on sustainability of resources while keeping the earth safe in terms of utilizing the wastes from industry in a useful manner.

\section{Material and methods}

\subsection{Tomato seedlings}

The tomato seedlings were obtained from a local commercial producer growing organic 'stick tomatoes'. They were received in almost uniform shapes and sizes in small pots.

\subsection{The growth medium}

The growth medium was a liquid hydroponic medium (brand name Biovin ${ }^{\mathrm{TM}}$ ) specially formulated for tomato production and used in greenhouses for soilless tomato production. The medium ingredients were total organic material $45 \%$, total organic carbon $19 \%$, total Nitrogen $5 \%$, and dissolvable potassium $3 \%$ as $\mathrm{K}_{2} \mathrm{O}$. Liquid media was formulated (according to the formula provided by the supplier) such that $40 \mathrm{ml}$ of solution dissolved in 20 liters of water.

\subsection{The Algae}

The algae Chlorella vulgaris was grown in our laboratory in order to add to hydroponic medium, from a strain supplied from a Biotechnology company in U.S.A. It was suggested for use especially for mineral and high oil content such as in biodiesel production. This culture was kept in solid TAP medium as described by Andersen, as a stock culture and 
inoculated to liquid medium[14]. This culture kept growing under set conditions at 23 C on a shaker oscillating @110 rpm.

\subsection{Plant growth room design}

A system was constructed to achieve liquid hydroponics medium circulating and continuously feeding the plantlets in our laboratory. The pipes made from PVC with diameter $10 \mathrm{~cm}$ and $1,5 \mathrm{~m}$ length were used as the circulating system. In each pipe, 4 holes (w/ $5 \mathrm{~cm}$ diameter) were drained on top to hold small plastic pots used to receive the seedlings. The pipes were placed under LED lights (OSRAM LED Tubes 21W/865 ST8P-1, $5 \mathrm{M}$ ) specially constructed on the shelves.

The pumps were aquarium type pumps (Eiheim Compact motor 300) designed for pumping a capacity of 170-300 L/hr. One pump was placed on bottom of each plastic tank, holding approximately 20 liters of liquid medium.

The $\mathrm{pH}$ and $\mathrm{EC}$ readings were taken with a portable $\mathrm{pH}$ meter (ISOLAB accuracy for $\mathrm{pH}+-0.01$ and conductivity $2 \%$ ).The $\mathrm{pH}$ and EC (Electrical conductivity) values mere measured for the hydroponic solution and it was recorded at the beginning such that $\mathrm{pH}=7.56$ and $\mathrm{EC}=1120 \mu \mathrm{s}$. The growth room had temperature and humidity recordings and kept at a temperature of 24-25 C and approximately 43-45\% humidity.

The hydroponic system constructed in the growth room is shown in Figure 1. The growth of tomato plantlets in the soilless system in a netted pot is shown in Figure 2.

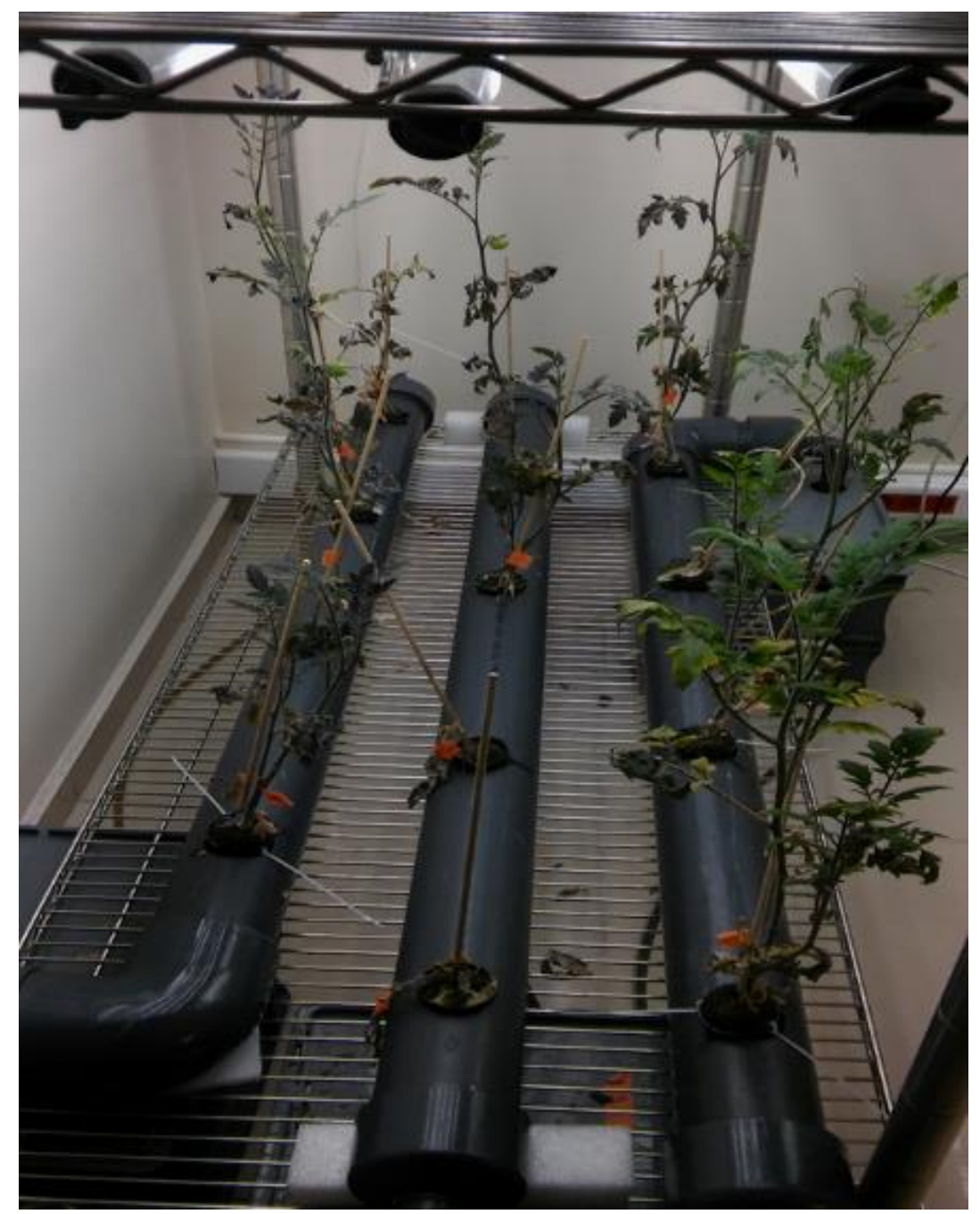

Figure 1 Hydroponic system for tomato plant nutrition in the plant growth room 


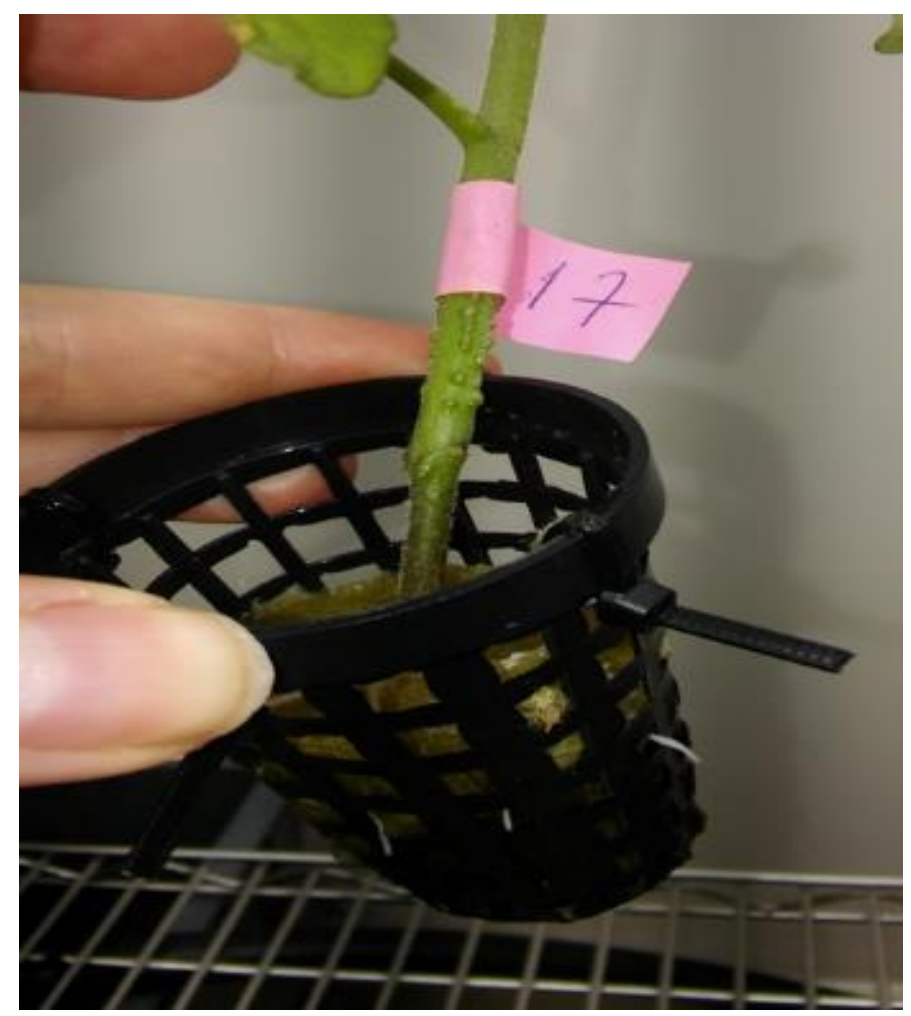

Figure 2 Tomato plantlet grown in a netted pot

The medium $\mathrm{pH}$ and EC values were recorded weekly and the medium level was observed. If the level dropped due to evaporation loss, a small amount was added to maintain the level. The medium in tanks ( 3 total) were replaced every 2 weeks with fresh medium. Experiment was checked if there was any contamination or adverse growth seen in fruits. Experiment was terminated after growth and harvesting of fruits was achieved (2 months period).

\subsection{Eggshell waste (ESW) treatment}

Egg shell wastes were collected by the students from consumed cooked eggs in dormitory cafeterias. They were cleaned from ESW membranes and dirt if any, and then put in the oven at $105 \mathrm{C}$ for sterilization of the shells. The shells turned to brownish color in the oven after about half hour. Afterwards they were crushed in kitchen type blender and ESW powder was obtained.

$\mathrm{The} \mathrm{CaCO}_{3}$ in eggshell should be converted to calcium which is available form for plant uptake. The acetic acid (Technical grade) is used for the purpose of Ca exposure for plants. ESW powder was put in 3\% acetic acid solution in a beaker enough to cover the surface and left overnight for exposure to acid. The following day, the acid was poured from the beaker leaving the powder and washed with water.

\subsection{The design of experiments}

The design of experiments in the growth room were based on three treatments:

1. Hydroponic medium + egg shell waste (ESW)

2. Hydroponic medium + algae (Algae)

3. Hydroponic medium only (Blank)

The eggshell powder (as explained above) drained \& weighed $15.4 \mathrm{~g}$ for one teaspoonful measure. From this ESW powder, 1 teaspoonful was used for each plantlets i.e. 4 tsps. put in each tank for 4 plantlets in one tube. 
The algae grown (as explained above) in $1 \mathrm{~L}$ flasks on the shaker were used to add to liquid hydroponic medium. 500 $\mathrm{mL}$ of algae was put in the 20 Liter solution of the tank.

Blank treatment had hydroponic only (no additions). Blank treatment can be considered as the control group of the experiment. The all tree treatments were placed under the light on the same shelf in the plant growth room.

\section{Results and discussion}

After harvesting of fruits, weight and number of tomatoes were recorded for each treatment (Table1). Mineral analysis was done by ICP instrument, (the model Perkin Elmer Optima ICPOES 7000DV). The analysis of minerals B, Ca, Cu, Fe, $\mathrm{K}, \mathrm{Mg}, \mathrm{Mn}, \mathrm{Mo}, \mathrm{Na}, \mathrm{P}$, and $\mathrm{Zn}$ were done. Table 2 and 3 shows the results of mineral analysis for plant stalk and tomato, respectively.

Table 1 Final wet weight of tomatoes

\begin{tabular}{|l|l|}
\hline & Tomato wt. (g) \\
\hline Algae & 11.31 \\
\hline ESW & 2.71 \\
\hline Blank & 7.27 \\
\hline
\end{tabular}

Table 2 Mineral analysis results for plant stalk

\begin{tabular}{|l|l|l|l|l|l|l|l|l|l|l|l|}
\hline & $\mathbf{B}$ & $\mathbf{C a}$ & $\mathbf{C u}$ & $\mathbf{F e}$ & $\mathbf{K}$ & $\mathbf{M g}$ & $\mathbf{M n}$ & Mo & Na & $\mathbf{P}$ & Zn \\
\hline ESW & 15,25 & 1418,75 & 4,12 & 37,38 & 27,07 & 1335,00 & 5,87 & 0,87 & 1074,75 & 1172,4 & 21,50 \\
\hline Algae & 17,00 & 1407,5 & 4,38 & 33,25 & 37,70 & 2043,75 & 10,62 & 1,12 & 1302,5 & 964,5 & 22,38 \\
\hline Blank & 17,25 & 943,00 & 3,62 & 70,50 & 34,75 & 1631,25 & 5,75 & 0,50 & 1199,88 & 1017,8 & 21,25 \\
\hline
\end{tabular}

Table 3 Mineral analysis results for tomato

\begin{tabular}{|l|l|l|l|l|l|l|l|l|l|l|l|}
\hline & B & Ca & Cu & Fe & K & Mg & Mn & Mo & Na & P & Zn \\
\hline ESW & 26,38 & 8942,5 & 2,25 & 23,63 & 30,92 & 1645,0 & 3,88 & 0,38 & 7895 & 272,5 & 110,75 \\
\hline Algae & 25,75 & 6788,75 & 3,62 & 16,25 & 30,62 & 1547,5 & 10,62 & 0,75 & 6487,5 & 319,13 & 95,12 \\
\hline Blank & 23,75 & 2773,75 & 2,00 & 35,25 & 12,47 & 1413,7 & 8,37 & 0,75 & 14250 & 307,13 & 38,12 \\
\hline \multicolumn{7}{c}{ \% Relative standard deviations (RSD): Zn; 0,46\%, Mn;1,28\%, Mg; $1,38 \%$ \%; $0,49 \%}$. \\
\hline
\end{tabular}

Note: Algae; Algae added, ESW; Egg shell waste added, Blank; no addition

The three treatments were compared i.e. algae added, ESW added and blank (hydroponic only) according to wet weight of harvested tomatoes results (Table1). Algae treatment gave the highest weight of tomato compared to others showing beneficial effect coming from algae. ESW gave the lowest weight because maybe ESW powder dissolution in hydroponics caused adverse effect i.e. the pH of medium with ESW decreased than hydroponic only. The uniformity and almost equal sizes of seedlings were achieved by the producer so their initial weights were not too different than each other. But, weighing isolated seedling individually was not possible.

The results were evaluated in terms of mineral content in the stalk and tomato. The results of mineral analysis for plant stalk were evaluated (data given in Table2). Both ESW and algae contributed to calcium content in the stalk positively and gave higher amounts than the control. Because our major aim was to add to calcium content in tomato in order to avoid diseases, calcium content in tomato was in major scope of the research. The algae addition seemed to have a 
positive effect on contribution of minerals for plant stalk, i.e. $\mathrm{Ca}, \mathrm{Cu}, \mathrm{K}, \mathrm{Mg}, \mathrm{Mn}, \mathrm{Mo}, \mathrm{Zn}$ values were found to be higher than the control. ESW treatments showed higher values than control in terms of $\mathrm{Ca}, \mathrm{Cu}, \mathrm{Mn}, \mathrm{Mo}, \mathrm{P}, \mathrm{Zn}$ minerals.

Mineral analysis for tomato (fruit) were evaluated (data given in Table 3). Results showed that both ESW and algae treatments contributed to calcium content positively and gave higher amounts than the control (Table3). Most minerals in tomato were found higher for algae and ESW added treatments, i.e. $\mathrm{Ca}, \mathrm{B}, \mathrm{K}, \mathrm{Mg}$, and $\mathrm{Zn}$ than the control.

The results were as expected from the literature [12] i.e. the minerals and weight were proposed to increase by use of algae for tomato plant. Also, the first part of our research in soil [13], showed increased mineral contents by addition of algae and ESW in soil.

Statistical analysis of the results (by Stata software) on the mineral analysis was not found to be significant, i.e. effect of enrichment of the soilless medium with algae or ESW was not significantly different than the regular medium.

\section{Conclusion}

Algae addition into soilless hydroponic medium was found to be beneficial for tomato plant growth and mineral enrichment, especially leading to increased calcium content in tomato. It can be suggested, if there is available algae biomass, using the nutrients of this biomass in soilless culture can promote the plant growth and nutrition.

Increase in calcium and some other minerals in tomato can be expected so it will be beneficial for the grower. Clean room free from insects, pesticides contaminants etc. and controlled temperature and humidity conditions, medium constituents are the advantages of soilless cultures. Benefits will come to environment safety and human health too, based on the controlled growth of soilless cultures in plant rooms or greenhouses.

Algae grown under controlled conditions is seen as clean and sustainable source and it is safe to add to growth medium. So, the system is suggested as a healthy, sustainable environment that can be controlled and beneficial for tomato plant nutrition.

\section{Compliance with ethical standards}

\section{Acknowledgments}

This research project was funded by Konya Food and Agriculture University, research Project. Thanks to Konya Şeker A.Ş. company for providing the liquid medium and the tomato seedlings for this project. Thanks to and Hakan Eligül and Mert Sudagidan, specialists, for growing the algae culture and constructing the set-up of the system and the undergraduate students Amine Yücekul, Haluk Koçak and Yaren Acir who worked in the laboratory.

\section{Disclosure of conflict of interest}

The author declared no conflict of interest during the research and envisage none would exist thereafter

\section{References}

[1] Zahan S, Rana KMS, İslam MDK, Afrin R, İslam T, Salam MA Int. Journal of Applied research. 2018; 4 3:134-139.

[2] Mustafa NS, Matter IA, Abdalla HR, El-Dahshouri MF, Moustafa YAF, Zaid NS The promotive effects of some natural extracts on vegetative characteristics and nutrient status of citrus lemon seedlings. Net Journal of Agricultural Science. 2019; 7 2:43-49.

[3] Soares M, Marto S, Quina M, Gando-Ferreira L, Quinta-Ferreira R. Evaluation of Eggshell-Rich Compost as Biosorbent for Removal of Pb(II) from Aqueous Solutions. Water, Air \& Soil Pollution. 2016; 227 5:1-16. doi:10.1007/s11270-016-2843-X

[4] Ahmad MJ Eggshell and coral wastes as low cost sorbents. Journal of Industrial \&Engineering Chemistry. 2012; 18:198-204

[5] Guru PS, Dash S Sorption on eggshell waste: A review. Advances in colloid and Interface science. 2014; 49-67 
[6] Mittal A, Teotia M, Soni RK, Mittal J Application of eggshell and egg shell membrane as adsorbents: A review. Journal of Molecular Liquids. 2016; 223:376-387.

[7] Oliveira D, Benelli P, Amante E A literature review on adding value to solid residues: Egg shells. Journal of Cleaner Production. 2013; 46:42-47.

[8] Easterwood GW Calcium's role in plant nutrition. Fluid journal. 2002; 1-3.

[9] Oceana-BA Rural development and environmental protection through the use of bio fertilizers in agriculture. Technology in society. 2016; 46:90-99.

[10] Aseri GK, Jain N, Panwar J, Rao AV, Meghwal, PR Bio fertilizers improve plant growth, fruit yield, nutrition, metabolism and rhizosphere enzyme activities of Pomegranate (Punica granatum L.) in Indian Thar Desert. Scientia Horticulturae. 2008; 117:130-135.

[11] Chang, KH Effects of chemical and organic fertilizers on the growth, flower quality and nutrient uptake of A. Andreanum. Scientia Horticulturae. 2010; 125:434-441.

[12] Aydoner-Coban G, Dasgan HY, Akhoundnejad Y, Ak-Cimen, B. Use of microalgae (Chlorella vulgaris) to save mineral nutrients in soilless grown tomato. ActaHortic. 2020; 1273:161-168. doi:10.17660/ActaHortic. 2020.1273 .22

[13] Erturk H. Effects of Egg Shell Waste and Algae Enrichment on Tomato Plant Nutrition in the Controlled Environment. Adv. Environmental Waste Management \& Recycling, 2020; 3 2:21-24.

[14] Andersen RA Algal culturing techniques, London: Elsevier Academic Press; 2005. 